\title{
Management of a Deregulated Power System with Voltage Stability Problem: Particle Swarm Optimisation Approach
}

\author{
S.Ramu ${ }^{1}$, P.Sridhar Reddy ${ }^{2}$, B.Shankar ${ }^{3}$
}

\begin{abstract}
This paper presents and utilizes an Improved Particle Swarm Optimization algorithm (IPSO) for reactive power management in restructured power systems. Reactive power procurement is modeled as a Security Constraint Optimal Power Flow (SCOPF), which incorporates a voltage stability problem. This is a major concern in power system control and operation. The model attempts to minimize the cost of reactive power procurement and energy losses as a main objective, while the technical criteria and voltage stability margin, especially, are treated as soft constraints. From a mathematical point of view, the reactive power market can be expressed as a nonlinear non-convex optimization problem with multi-local minima. In most cases, the non-convexity results in a failure of the mathematical-based optimization algorithm to _nd the global optimum. Thus, the PSO, a powerful heuristic searching algorithm, is developed and implemented to _nd the global optimum of the reactive power market objective function. The feasibility of the methodology (IPSO) is tested over an IEEE30 bus system, while the obtained simulation results are compared with the gradient-based approach, using General Algebraic Modeling System (GAMS) software, the original PSO and another evolutionary programming called a Genetic Algorithm (GA). The results demonstrate that the IPSO can converge to better feasible solutions with less iteration and can be successfully used for reactive power scheduling in deregulation environments.
\end{abstract}

Key Words: Particle Swarm Optimization algorithm (IPSO), General Algebraic Modeling System (GAMS), Genetic Algorithm (GA).

\section{INTRODUCTION}

During past two decades electric utilities have faced the upheaval of moving toward deregulation. It has always been its ambition of creating a clear structure in which rivals are allowed to do free enterprise in trading of electricity.

Accordingly, in this new era economical rules and electricity market legislations have a big effect on secure operation of power systems. This means that, presence of a market independent entity is vital while it should only be in charge of security and stability of power system operation. This entity, called ISO, which is acronym for Independent System Operator [1]. Major task of ISO corresponds to prospect ancillary services requirements which are necessary for reliability enhancement of the system. ISO is also responsible for ancillary services procurement [2,3]. Reactive power is one kind of ancillary service that has significant effects on active power trading indirectly. Reactive power is utilized for different purposes e.g voltage profiles amelioration, power loss reduction and lessening occupied capacity of the transmission network. In general, a good reactive power management system increases the performance of transmission lines as unique paths for physical operation of electric power transactions.

From Economical points of view, ancillary services had better be provided in a market structure than obligatory as it is operated in vertically integrated system. In recent years many researches are carried out concerning reactive power management and pricing in restructured power systems. In [4,5] applicable methods for determination of reactive power costs are discussed. In [6] a security constraint optimal power flow (SCOPF) is presented for reactive power management of NGC power system. In proposed method reactive power cost is modeled as a quadratic function of generators' reactive power outputs and linear programming is used to solve model and determination the reactive powershared among participants along with prices.

Considering social welfare objective for active power market in [7] it tries to dispatch reactive power in such a way power market get better performance as much as possible. It also assumes that active power consumptions are proportional to the price and obey an exponential function. Based on this strategy one can easily distinguish that reactive power price is determined indirectly and it depends on active power activities. Lagrangian multipliers are used for settlements of active / reactive power commodity. Reference [8] exploits an OPF based structure to show that reactive power pricing extremely depends on chosen objective for its dispatching purposes. Data analysis of [8] declares that it had better reactive power price be determined in a separate structure and independent of active power market objectives.

Investigation of methods presented in above articles reveals that in all cases, reactive power is optimized around current operating point of power system after clearing active power market or simultaneous with it. In other words there is less attention to reactive power reserve necessary for preventing of voltage collapse occurrence following perturbation in loads or other events.

This paper presents a method in which providing of efficient reactive power reserve is also considered in price determination. Therefore, conventional OPF formulation is modified in somehow; voltage stability criterion can be modeled within reactive power market equations. In proposed structure, reactive power costs is to be minimized independently of active power activities. Particle Swarm Optimization Algorithm is used for solving OPF based market structure implemented on WSCC 9 bus test system to show capabilities of the procedure into a market based power system 
management.

\section{REACTIVE POWER COST EVALUATION}

Different methods are reported in [4,5] for reactive power cost might incur by generators, switched capacitors, Static VAR compensator, operation of ULTC and etc. Opportunity cost is formed a significant part of reactive power costs. Reactive power operation costs are negligible unless a generator is obliged to reduce active power outputs for supporting more reactive power. This situation may occur while a generator is operated near or on its maximum capability curve as shown on figure 1. From this figure, one can find that generator must reduce its output power $\mathrm{PA}$ to $\mathrm{PB}$ for increasing its reactive outputs from QA to $\mathrm{QB}$.

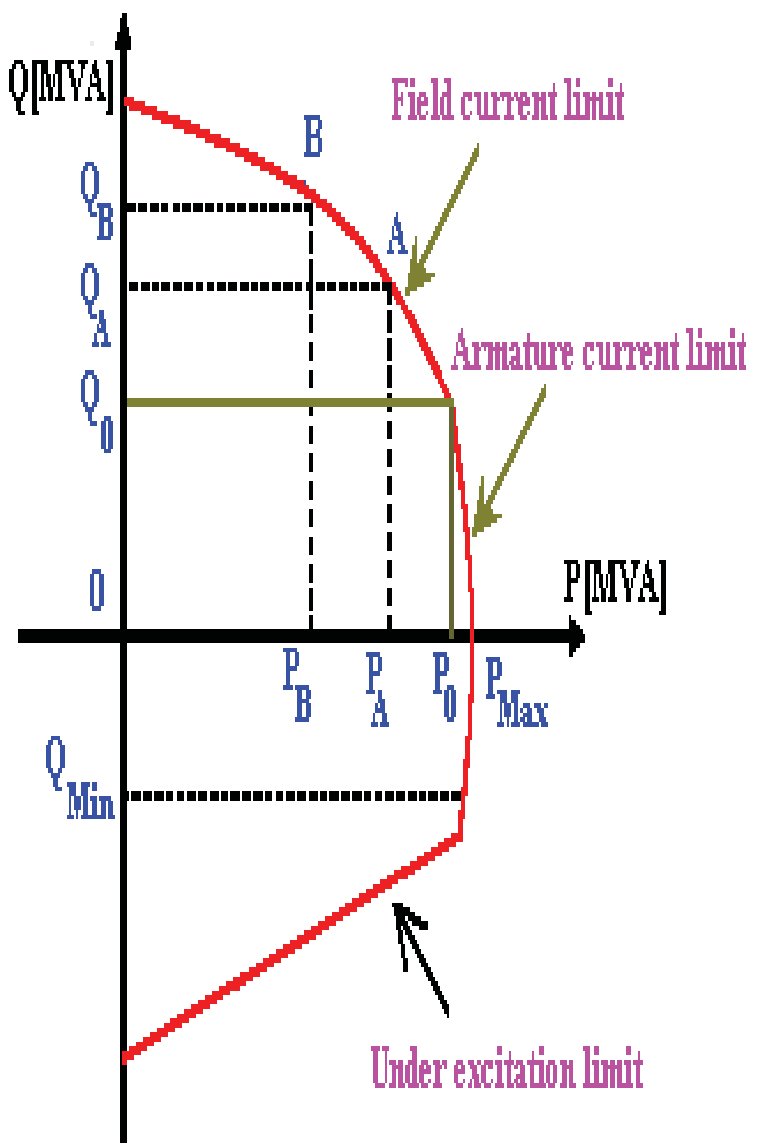

Fig1. Capability curve of generator used to calculate voltage stability margin $(\mathrm{Z})$ :

Therefore in this paper lost opportunity cost of a generator as a part of reactive power cost is modeled as below [8].

$\operatorname{Max}$

$$
\begin{aligned}
& \mathrm{P}_{\text {gi }} \square \square \mathrm{P}_{\mathrm{Li}} \square \square \square \mathrm{V}_{\mathrm{i}} \square \square \mathrm{V}_{\mathrm{j}} \mathrm{Y}_{\mathrm{ij}} \operatorname{Cos}\left(\square \square{ }_{\mathrm{ij}} \square \square \square \square \mathrm{j}\right. \\
& \mathrm{C}_{\text {gqi }}\left(\mathrm{Q}_{\text {gi }}\right) \square \square\left[\mathrm { C } _ { \text { gpi } } \left(\mathrm{S}_{\text {gi max }} \sqrt{S_{\text {gimax }}^{2}-Q_{g i}^{2}}\right.\right. \\
& ) \square \square \mathrm{C}_{\text {gpi }}()_{\mathrm{i}}\right] \mathrm{K}_{\text {gi }}(1)
\end{aligned}
$$

Where:

$\mathrm{Q}_{\mathrm{gi}} \quad \square \square \mathrm{Q}_{\text {Limin }} \downarrow \downarrow \mathrm{V}_{\mathrm{i}} \| \square \downarrow \mathrm{U}_{\mathrm{j}} \max \quad \mathrm{Y}_{\mathrm{ij}} \quad \operatorname{Sin}\left(\square \mathrm{ij} \quad \square \square \square \square{ }_{\mathrm{j}}\right.$ i )

$\mathrm{C}_{\text {gpi }}\left(\mathrm{P}_{\text {gi }}\right.$ ) $\quad \square \square \square \mathrm{aP}_{\text {gi }} \quad \square \square \mathrm{bP}_{\text {gi }} \quad \square \square \mathrm{C}$ is active power production cost.

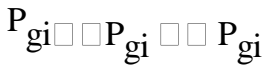

$\mathrm{Q}_{\mathrm{gi}}$ : is reactive power output of a generator $\mathrm{i}$.

$\min$

$$
\begin{aligned}
& \text { gi } \square \square \mathrm{Q}_{\mathrm{gi}} \square \square \mathrm{Q}^{\max } \\
& \mathrm{S}_{\text {gi max }} \text { : is maximum apparent power of generator } \mathrm{i} . \\
& \mathrm{K}_{\mathrm{gi}} \text { : is profit rate of active power, usually between } 0.05 \sim 0.1 . \\
& { }_{\text {mini }} \square \square \square{ }_{\mathrm{I}} \max _{\varpi} \\
& \square \square \square \mathrm{i}
\end{aligned}
$$

On the other hand reactive power provided by static VAR compensators is evaluated as following:

Where:

$$
\begin{aligned}
& \mathrm{P}_{\text {gi }} \square \square \mathrm{P}_{\text {gi }} \square \square \square \square \mathrm{P}_{\mathrm{si}} \square \\
& \mathrm{C}_{\mathrm{ci}} \square \square \mathrm{r}_{\mathrm{cj}} \mathrm{Q}_{\mathrm{cj}} \\
& \text { Where: } \\
& \mathrm{P}_{\mathrm{Li}} \square \square \mathrm{P}_{\mathrm{Li}} \square \square \square \mathrm{P}_{\text {Di }} \mathrm{P}_{\text {gi }} \text {, }
\end{aligned}
$$

Qgi : Active/Reactive power generation output.

Rcj: is unit cost of reactive power in \$/MVAR

$\mathrm{PLi}$, QLi : Active/ Reactive power consumption.

$Q_{c j}$ : is amount of supplied reactive power in MVAR.

\section{VOLTAGE STABILITY MARGIN: DEFINITION AND CALCULATION}

In a real power system, there are separate voltage control areas in which voltage magnitude are regulated by means of equipments such as generators, synchronous condensers, capacitors, reactors and etc. Modeling these equipments along with their control circuits are necessary for exact studies of power system. In this case one can solve following Differential Algebraic Equations (DAE) for precise simulation [9]:

$\mathrm{x} \square \square \mathrm{f}(\mathrm{x}, \mathrm{y}, \square, \square)$

while voltage stability margin satisfies its predefined value.

$0 \square \square \mathrm{g}(\mathrm{x}, \mathrm{y}, \square, \square)$

In this formulation $\mathrm{x}, \mathrm{y}, \mathrm{q}$ and $\mathrm{Z}$ represent state variables, algebraic variables, control parameters and constant parameters in power system respectively. Solving following equations give the equilibrium point of the power system in normal condition.

These objectives can be modeled as following:

$$
\begin{aligned}
& \text { Min } \square \mathrm{C}(\mathrm{Q})^{\mathrm{P}_{\mathrm{gi}}} \mathrm{P}_{\mathrm{Li}} \square \square \mathrm{V}_{\mathrm{i}} \square \mathrm{V}_{\mathrm{i}} \mathrm{Y}_{\mathrm{ij}} \operatorname{Cos}\left(\square \square_{\mathrm{ij}} \square \square \square \mathrm{j} \square\right) \\
& \text { Qgi } \square \square \text { QLi } \square \square \square \square \text { Vi } \square \square \text { V jYijSin( } \square \square \mathrm{ij} \square \square \square \square \text { j } \\
& \square \square \square \square \mathrm{i}) \\
& 0 \square \square \mathrm{f}(\mathrm{x}, \mathrm{y}, \square, \square) \\
& 0 \square \square \mathrm{g}(\mathrm{x}, \mathrm{y}, \square, \square) \quad \text { (4) } \\
& \mathrm{P}_{\text {gi }} \square \square \mathrm{P}_{\text {gi }} \square \mathrm{VSM}^{\mathrm{DEF}} \mathrm{P}_{\mathrm{Si}}
\end{aligned}
$$


Voltage instability usually may occur following some one line diagram shown in figure 3.

perturbation in loads or generations connected to the system. Many studies have shown that voltage stability phenomenon can be examined satisfactory regardless of considering power system dynamics (equations 4). In this case voltage stability margin is defined as difference between maximum transferring power that system can be tolerated and power of normal operation. This margin can be evaluated by CPFLOW method represented in $[10,11]$. In this paper an optimization method is

In above equations PS and PD indicate direction of incremental power generation and consumption respectively. It is also assumed that loads are increased while power factors are kept constant.

Equality constraints are nodal power flow equations while inequalities represent limits of resources and some technical characteristics.

\section{OPTIMAL REACTIVE POWER MANAGEMENT: MATHEMTICA FORMULATION}

In this section an OPF based market structure for reactive power procurement is presented. It is assumed that active power is traded in bilateral contracts and ISO is only informed of transactions quantities. Hence, ISO should provide reactive power for supporting electricity transactions in minimum cost. In above equations ?C (Q) represents reactive power cost and $\mathrm{Z}$ in equations 6 is substitute with VSM DEF.

\section{PARTICLE SWARM OPTIMIZATION ALGORITHM}

Particle swarm optimization algorithm (PSO) is a new evolutionary computation technique motivated by simulation of social behavior [12-13]. This method is well developed for optimization of continuous nonlinear functions. PSO is similar to Genetic Algorithm in that the system is initialized with a population of random solutions. In PSO agents share their best information of previous experiences of searching feasible solution space to the other ones to help neighbors for finding global optimum point. Referring to fig 3 one can pursue PSO's algorithm as following:

Step1- a number of agents as initial population is positioned in searching space of the problem. Their initial velocity is also assigned to them. Populations are categorized into different classes on their geometric distance from each other. Step2 - objective function is evaluated for each agent. Then the best point of separated groups is determined by sorting of cost value in descending order. This point can be considered as relative global point in each group.

Step3 - In this stage the best point among all searching group will be distinguished. Moreover the best point experienced by each agent is also saved in memory of particles. The first information is referred to global optimum point of each group while the second can be referred to local optimum information. According to these data, particles are motivated to move toward following direction:

\section{SIMULATION AND RESULTS}

Presented method is implemented on WSCC 9-bus test system. System characteristics are presented in table 1 along with its
Table1. Transmission lines data

$\begin{array}{ccccc}\text { From } & \text { To } & \text { R (p.u.) } & \text { X (p.u.) } & \text { B (p.u.) } \\ 1 & 4 & 0 & 0.0576 & 0 \\ 4 & 5 & 0.017 & 0.092 & 0.158 \\ 5 & 6 & 0.039 & 0.17 & 0.358 \\ 3 & 6 & 0 & 0.0586 & 0 \\ 6 & 7 & 0.0119 & 0.1008 & 0.209 \\ 7 & 8 & 0.0085 & 0.072 & 0.149 \\ 8 & 2 & 0 & 0.0625 & 0 \\ 8 & 9 & 0.032 & 0.161 & 0.306 \\ 9 & 4 & 0.01 & 0.085 & 0.176\end{array}$

$\mathrm{V}^{\mathrm{t} \square 1} \square \square \mathrm{V}^{\mathrm{t}} \square \square \square \square\left(\mathrm{P}_{\mathrm{gj}} \square \square \mathrm{X}_{\mathrm{i}}\right) \square \square \square \square\left(\mathrm{P}_{\mathrm{i}} \square \square \mathrm{X}_{\mathrm{i}}\right)$ (8)

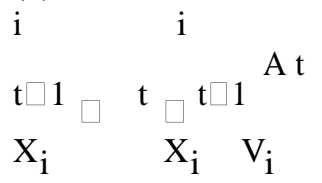

Where:

Vi And

$\mathrm{X} \mathrm{t}$ are current velocity and position vectors while index $\mathrm{t}+1$ is referred to next direction and position of particles. a and $\mathrm{p}$ are random numbers in the range $[0,1]$. Pgi is global position in each group and Pli is local optimum point found by agent $i$.

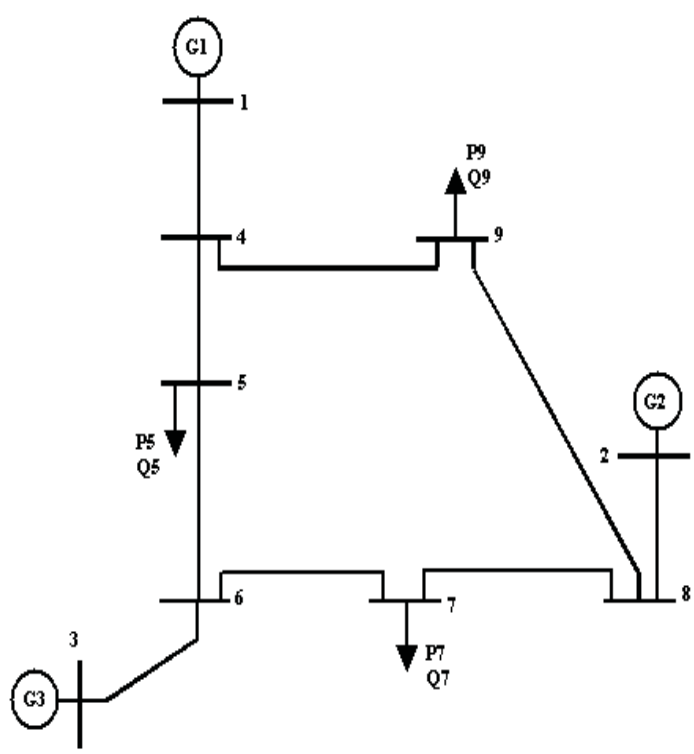

Fig3. WSCC 9-bus test system: Online diagram

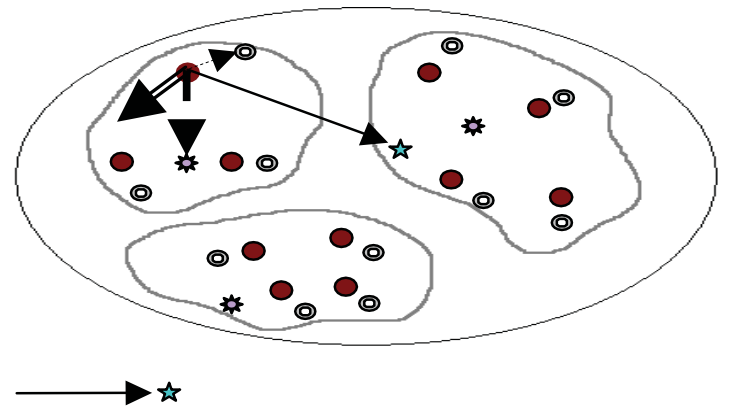




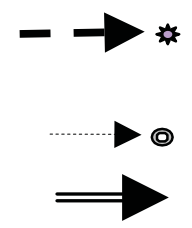

Direction toward optimum point of each group Direction toward local optimum point in each group Resulting vector calculated by equation (8)

Fig2. PSO algorithm: searching procedure.

\begin{tabular}{|l|l|c|c|c|c|}
\hline & & Load1 & Load1 & Load1 & \\
\cline { 2 - 6 } & $\begin{array}{l}\text { Genera } \\
\text { tor1 }\end{array}$ & 30 & 0.0 & 37 & 67 \\
\cline { 2 - 6 } & $\begin{array}{l}\text { Genera } \\
\text { tor2 }\end{array}$ & 0.0 & 75 & 88 & 163 \\
\hline $\begin{array}{l}\text { Direction toward } \\
\text { global optimum } \\
\text { point }\end{array}$ & $\begin{array}{l}\text { Genera } \\
\text { tor3 }\end{array}$ & 60 & 25 & 0.0 & 85 \\
\hline
\end{tabular}

Table2. Bilateral Contracts

For this test system bilateral contract quantities are reported in table 2 .

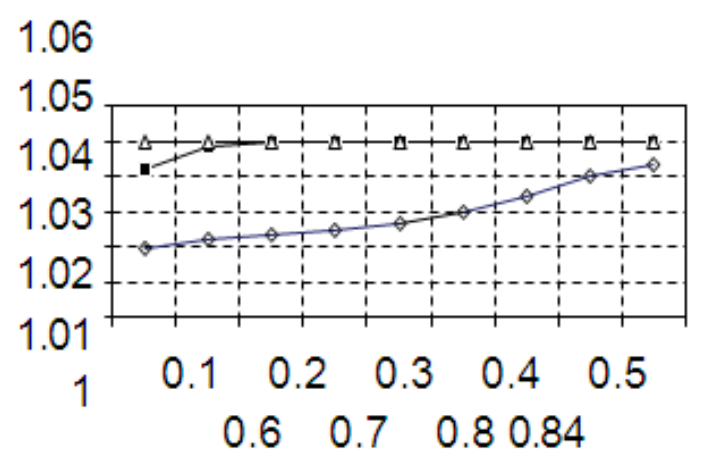

\section{V.S.M}

Fig4. Generator's terminal voltages variation

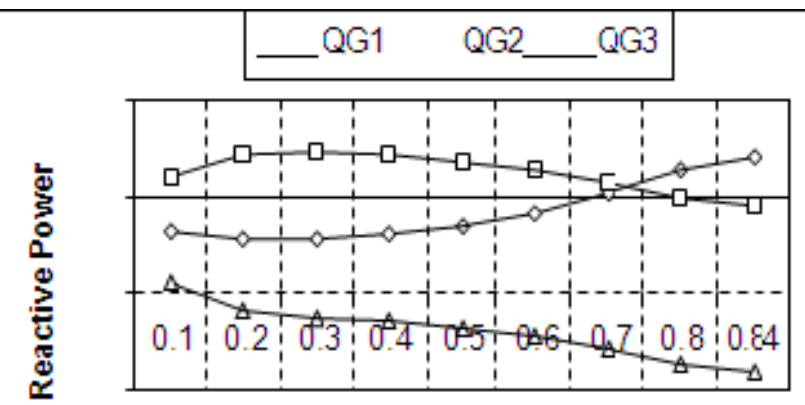

Fig5. Generator's reactive power outputs variation

For the sake of investigation, VSM is varied from 0.1 p.u. to 0.84 p.u. and at each step optimal power flow equations 7 is solved sequentially. Reactive power outputs of generators and their voltage variations are important results that presented graphically in figures 4 and 5. Generators' reactive power outputs are controlled indirectly by adjusting their terminal voltages.

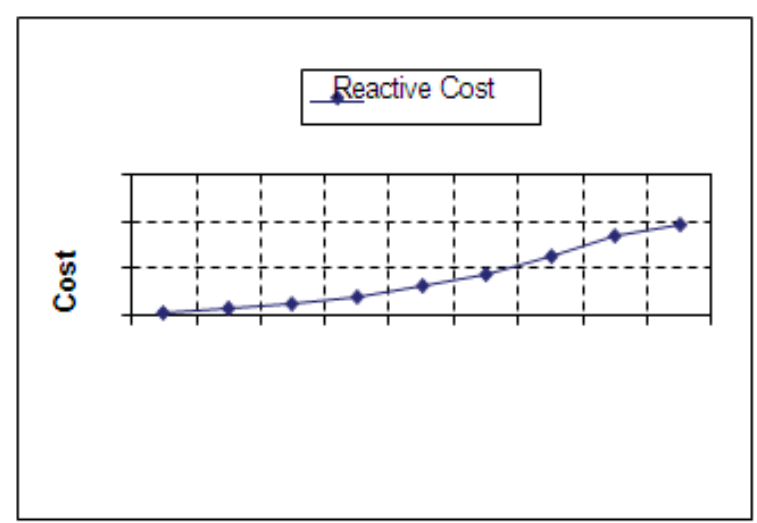

Fig6. Cost of reactive power procurements respect to VSM

\section{CONCLUSION}

In this paper a method for reactive power reserve management in a restructured power system is presented. Reactive power cost minimization is assumed to be the main purpose of the ISO in purchasing reactive power. For better operation of power system, reactive power reserve is to be dispatched while definite voltage stability margin defined in proposed OPF formulation of reactive power market is fulfilled. Therefore ISO ensures of security and stability of the power system during normal operation and critical period while cost of reactive power procurement is minimized.

\section{ACKNOWLEDGMENT}

The authors gratefully acknowledge the support provided by parents, friends and colleagues who helped for done this work We would like to express our sincere thanks to guide Dr.P.Sridhar Reddy for giving his moral support, encouragement and motivation for allowing and providing us facilities to do this work.

\section{REFERENCES}

[1] M. Shahidehpour and M. Alomoush, "Restructured Electric Power System," 1nd ed. New York: Marcel Dekker, 2001.

[2] Eric.Hirst.and Brendan Kirby, "Creating Competitive Market for Ancillary Services", Oak Ridge National Laboratory, ORNL/Con448, October 1997.

[3] New York Independent System Operator Ancillary Services Manual, 1999.

[4] John.W.Lamont and Jidn Fu, "Cost analysis of Reactive Power Support", IEEE Transaction on power System. Vol. 14, No. 3, PP. 890-898, August 1999.

[5] Shangyou Has and Alex Papalexopoulos, "Reactive Power Pricing and Management", IEEE Transaction on Power System, Vol. 12, No. 1, Feb. 1997.

[6] N.H. Dandachi etal, "OPF for Reactive Pricing Studies on the NGC System.", IEEE Transaction on Power System, Vol. 11, No. 1, PP. 226232, Feb. 1996.

[7] Joon Young choi, Seong-Hnong Rim and Jong-Kenu Park, "Optimal Real time pricing of Real and Reactive Powers", IEEE Transaction on Power Systems, Vol. 13, No. 4, November 1998.

[8] Y. Dai, etal, "Analysis of Reactive Power Pricing under deregulatin", Proceeding of IEEE power Engineering Society summer Meeting Seattle, USA, 2000, Vol. 4, PP. 2167-2167.

[9] I. Dobson, "Observations on the geometry of saddle node bifurcation and voltage collapse in electric power systems", IEEE Trans. Circuits \& Systems, Part1, vol.39, no.3, Mar.1992, pp.240-243.

10] V.Ajjarapu, C.Christy, "The continuation power flow: a tool for steady state voltage stability analysis", IEEE Trans. Power Systems, vol.7, no.1, Feb.1992, pp.416-423 